\title{
A REVIEW OF METHODS FOR EXCITATION FORCE RECONSTRUCTION
}

\author{
Krzysztof MENDROK, Ziemowit DWORAKOWSKI \\ AGH University of Science and Technology, Department of Robotics and Mechatronics, \\ al. Mickiewicza 30, 30-059 Krakow, Poland, e-mail: zdw@agh.edu.pl
}

\begin{abstract}
In many mechanical systems research scenarios, including in particular control and monitoring of mechanical devices, reconstruction of external loads acting on a system is a matter of great importance. The paper provides taxonomy and review of available dynamic load identification methods in cases when a direct load applied to the structure is required to be reconstructed. Methods based on frequency and time domains as well as those relying on statistical and soft computing approaches are described. The authors present methods in possibly broad manner, including initial assumptions, workflow and some of the equations. For that reason, reader is able to initially assess methods' potential in particular applications and choose the method which best fit his needs.
\end{abstract}

Keywords: load reconstruction, inverse problem, force identification, structural health monitoring

\section{PRZEGLĄD METOD REKONSTRUKCJI SIŁY WYMUSZENIA}

Streszczenie

W wielu scenariuszach badawczych dotyczących układów mechanicznych, w szczególności sterowania i monitorowania urządzeń mechanicznych, rekonstrukcja obciążeń zewnętrznych działających na układ ma ogromne znaczenie. W artykule przedstawiono taksonomię i przegląd dostępnych metod identyfikacji obciążeń dynamicznych bezpośrednio przyłożonych do obiektu na podstawie mierzonych sygnałów odpowiedzi. Opisano metody operujące w dziedzinie częstotliwości i czasu, a także te oparte na podejściu statystycznym i naturalnych metodach obliczeniowych. Autorzy przedstawiają metody w możliwie szeroki sposób, uwzględniając wstępne założenia, sposób postępowania i niektóre równania. Z tego powodu czytelnik jest $\mathrm{w}$ stanie wstępnie ocenić potencjał metod w poszczególnych aplikacjach i wybrać tę, która najlepiej odpowiada jego potrzebom.

Słowa kluczowe: rekonstrukcja wymuszenia, problem odwrotny, identyfikacja siły, monitorowanie stanu struktur

\section{INTRODUCTION}

The last twenty years resulted in a rapid development of the structural health monitoring (SHM) and control systems. The classic SHM system has a structure presented in Figure 1 [1].

It is a hierarchical structure, where at the lower level SHM system handles management of the monitoring of sub-systems. The results obtained at this level are helpful in taking decisions concerning the way of exploiting and maintenance of a given subgroup. The execution part consists of three basic modules:

- a diagnostics module,

- a module monitoring operating conditions, external excitation forces in particular.

- a database containing material models and damage accumulation models.

A classic control scheme has a structure presented in fig. 2. In many typical control scenarios - in particular when control setup is used for dealing with vibration control, identification of external disturbation can significantly benefit the control algorithm. It is especially important when dealing with nonlinear dynamics or time-varying systems.

Surprisingly, although much work has been devoted to both detecting damage in case of SHM systems and developing control algorithms in case of control systems, in neither of these areas a large comprehensive review of force identification techniques has been provided. In fact, the review by [2] is the only one that provides recent overview on the subject. That fact is particularly disturbing as, in the opinion of the authors, reliable prediction of damage growth in SHM or reliable control of nonlinear systems is impossible without an external force identification component [3].

In order to compensate for these disparities, the authors present an attempt to systematize the load identification methods and present an overview of these methods. It is prepared in such a way that based on its reading, the reader could conduct a preliminary assessment of algorithms and choose best for his needs. 


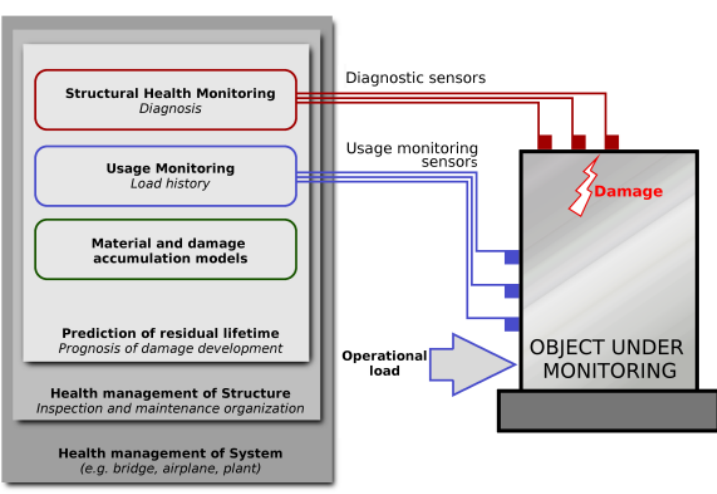

Fig. 1. Hierarchical scheme of an SHM system structure

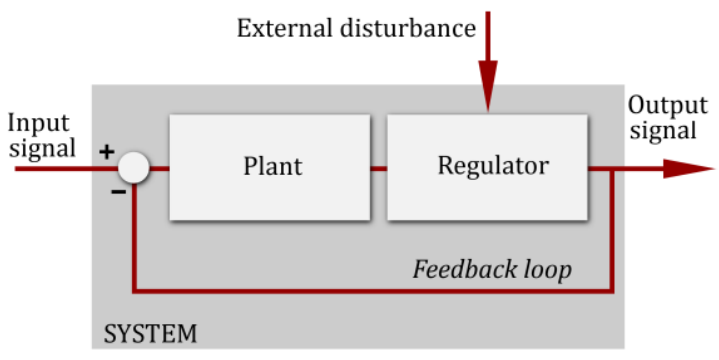

Fig. 2. Basic control scheme

Consecutive methods are therefore not only mentioned, but their mechanism of action is briefly described taking into account the design and calculation schemes. In addition to review by [2], authors focus not only on statistical approach, but also provide wider scope of possible force reconstruction methods, including time and frequency domain ones as well as those that are based on soft computing approach. Issues related to regularization were not included in scope of the article, as the comprehensive reviews of that area were already provided [2, 4].

The organization of this review is as follows: Section 1 provides introduction to the subject, section 2 introduces taxonomy of load reconstruction methods, sections 3,4 and 5 describe methods based on frequency, time-domain and statistical dependencies, respectively, section 6 provides brief description of soft-computing methods used in scope of force identification, finally, section 7 concludes the article.

\section{SOURCES OF DATA AND METHODS' TAXONOMY}

Vast majority of load identification methods use as inputs data that are acquired using accelerometers. However, velocity measurements or displacement measurements can also be used to this end. The velocity measurements are usually performed with laser vibrometers [5], the displacements using e.g. vision systems [6]. However, both these non-contact solutions require expensive equipment and complex setup procedures which hinder their practical applicability. The load can also be derived from local strain measurements which, again, can be performed using a variety of ways including e.g. vision systems [6], x-ray measurements [7] or others. For a good review of this area reader is referred to work by Grediac et al. [8] The most-well-known division of force identification methods is based on differences in the type of estimation algorithms (See fig. 3).

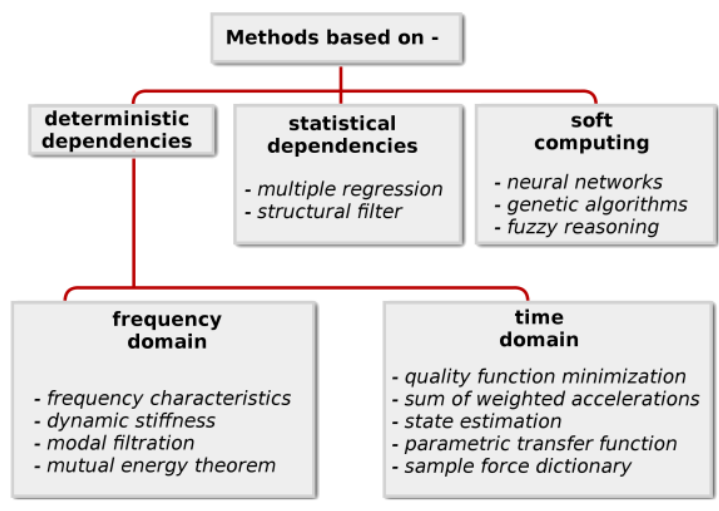

Fig. 3. Taxonomy of load reconstruction methods

The presented methods have different assumptions regarding applicability and they are presented in the following subsections. Generally, it can be stated that the methods from the deterministic group, which are based on linear models, are suitable for such systems. For nonlinear systems, soft-computing-based methods are proposed.

\section{FREQUENCY DOMAIN METHODS}

In physical systems, where forces present have a harmonic character (are generated by imbalance of rotating machines parts), or where no precise time histories of force excitation are needed, but only amplitude and frequency distribution (transfer path analysis, analysis of fatigue wear), applying methods in frequency domains for force identification is reasonable. They are simpler, and as such require less computational power. This feature is significant when it is necessary to perform identification in real time.

\subsection{Methods based on frequency characteristics}

This is probably the most popular method of excitation forces identification. Its application can be found in multiple papers [9-12] Its principle of operation can be presented as follows: performing measurement of the spectrum $Y(\omega)$ of responses at a certain number of measurement points $n$ allows the identification of the vector of forces $F(\omega)$, designating the pseudo-inverse matrix of the matrix of FRFs $H(\omega)$ (of the size $n \times m$ ), according to the dependencies:

$$
F(\omega)=[H]^{+}(\omega) \cdot Y(\omega)
$$

Some elements of the matrix $[H(\omega)]$ can be designated directly with experiments using, for example, the method of impulse test. It should be noted that if, in the considered cases, the Maxwell principle of reciprocity is met for the object, the 
impulse excitation can be applied both at the point in which the force is present, and at the point of signal response measurement (then the signal response is measured at the point and in the direction of the forces present). Designating experimentally all the required FRFs is not possible due to, among others, the difficulties of exciting vibration of the object at a tangent to its external surface without implementing local modification of the object. This creates the necessity to apply, for the definition of certain elements of the matrix $[H(\omega)]$ a modal model of the considered object. In modal tests, usually 1,2 or very rarely 3 or more rows or columns of the matrix $[H(\omega)]$ are designated. The remaining elements are defined by assuming the reciprocity principles. The matrix of FRFs can also be synthesized on the basis of a FEM model. Because the FRF matrix $[H(\omega)]$ in general is not square $(n \times \mathrm{m})$ it cannot simply be inverted, Therefore pseudo-inversion with SVD or MoorePenrose algorithm should be applied. In cases when the required FRFs of the object are unavailable, they can be synthesized on the basis of knowledge of the object's FE model [13] or on the basis of a modal model [10].

Another method based on the frequency characteristics is active path tracking [14]. The best fit between calculated responses and measured ones is achieved using the least squares method.

When the defined objective function is met, it can be accepted that the actual forces present in the transfer paths of propagating energy are equal to the values assumed in calculations. By using this method, knowledge of the structure is especially important in order to accurately identify all the places where energy is transferred from the source to the place where the response is measured.

\subsection{Dynamic stiffness method}

Another method of force identification on the basis of measuring responses operating in the frequency domain is the method of dynamic stiffness [15]. It may be used where the element connecting the source of the force with the rest of the structure has a lower stiffness than the stiffness of the rest of the system. For this type of elements the dynamic stiffness characteristic $K(\omega)$ is designated, and force is expressed on the basis of its knowledge. In the presented method, displacement of both sides of the connecting element is measured. on the side of the force source - $Y_{s}(\omega)$ and on the structure side, the receiver of the transferred energy - $Y_{t}(\omega)$.

The measurement of both spectra $Y_{s}(\omega)$ and $Y t(\omega)$ must be performed simultaneously. When designating dynamic stiffness, the connecting element should be subjected to initial force similar to the one that is present under normal work conditions in the structure.

\subsection{Modal filtration method}

The modal filter is a tool for extracting the modal coordinates of each individual mode from the system outputs by mapping the response vector from the physical space to the modal space [16-18]. Application of the modal filter to force identification proceeds in four major steps [19]:

1. Transfer the outputs of the system from physical coordinates to modal coordinates using modal filters.

2. Determine the number of uncorrelated system inputs based on the weighted modal coordinates.

3. Locate these unknown inputs.

4. Calculate the amplitude of these inputs.

The structure of the $k$-th modal filter, which corresponds with the $k$-th pole of the transfer function $H(\omega)$, requires introduction of a reciprocal modal vectors (RMVs) denoted as $k$. RMVs should be orthogonal with respect to the modal vectors and thanks to this they can be applied to the decomposition of the system responses to modal coordinates. Then, the excitation force can be calculated from the formula given in a matrix form:

$$
[F]=[\Phi]^{T+}[\Pi]
$$

where $[\mathrm{F}]$ refer to excitation forces matrix (its columns are nonzero vectors only for locations where the excitation force appeared), [Ф] refer to the modal vectors matrix and $[\Pi]$ denotes matrix which contain vectors of weighted modal coordinates.

\subsection{Method based on mutual energy theorem}

In 1892 Heaviside formed the mutual energy theorem [20]. This is used in acoustics to identify the sources of sounds in rooms [21]. This method was also used to estimate excitation forces in mechanical structures in the frequency domain [22].

To illustrate the method let's assume that four measurement points and four experiments are performed: the procedure and the way of conducting the experiments is presented in fig. 5 .

Then, dependency used to estimate the force takes the form

$$
F_{a}=\left[X^{-1} F Y_{a}^{\&}\right.
$$

Where: $F_{a}$ refers to identified force vector, [ $\&$ ] refers to matrix of responses velocities measured in consecutive experiments and consecutive points and $F_{a}^{\&}$ refers to vector of power calculated as a product of known forces from consecutive experiments and velocity caused by unknown identified force.

The method can be used only for linear systems.

\subsection{Quality function minimization method}

This method belongs to the most often used iterative methods [23-25]. It may be used for reconstructing the force time history on the basis of knowledge of responses. In particular, it is suitable for the identification of impulse force. It is based on the minimization of the objective function as a 
measure of the fit between the measured response signal and the calculated one. We can define the objective function as a difference between the measured response $y$ to the identified force and the response calculated $q$ by the simulation of the model of the system.
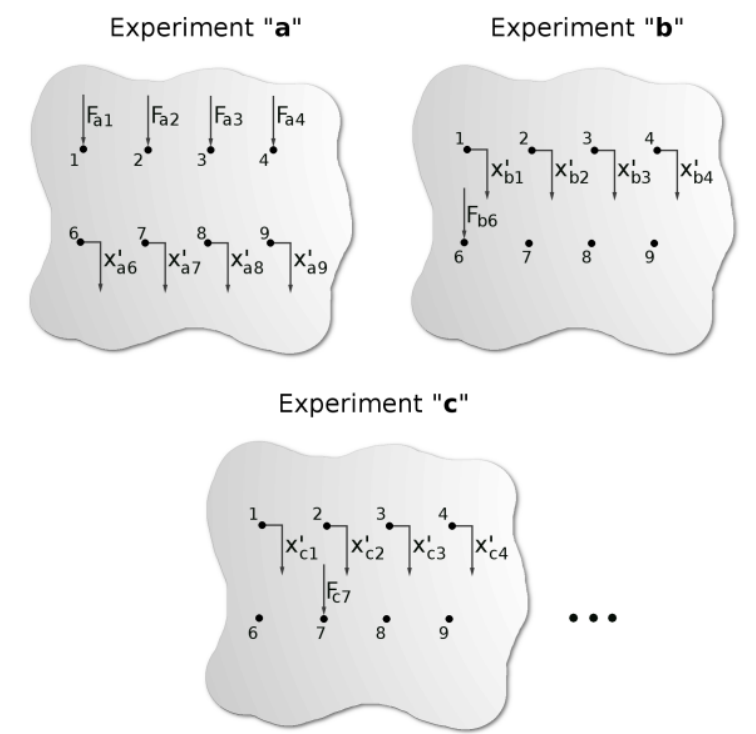

Fig. 4. The consecutive experiments necessary for the application of the mutual-energytheorem-based method

\section{TIME DOMAIN METHODS}

Another method which identifies load with use of minimization of quality function is presented in the paper by [26]. Comparing with other researches, the method is applicable to fully general case. It can be applied to both linear and elasto-plastic systems, the second class of systems is solved with use of virtual distortions method. The virtual distortions method proposed by [27]. The concept of reanalysis of a structure with modified parameters using fields of virtual distortions and an influence matrix is presented. This enables the calculation of updated structure responses under the influence of defined stresses, whose parameters undergo change. These changes are modeled by a field of virtual distortions placed on the structure, without the necessity of repeating the stiffness matrix calculations. Another level of method generality is presented by its ability to deal with underestimated cases. The identification is formulated analytically as a complex optimization problem: find the equivalent impact scenario that:

1. minimizes the potentially pre-conditioned mean-square distance between simulated and measured dynamic responses in sensor locations and

2. is optimum according to given heuristic conditions.

With the objective function defined in either of these ways, it is necessary to select the methods for its minimization. Here, methods based on dynamic programming $[22,23,28]$, evolutionary algorithms
$[24,29]$ or others [30,31] are applied. The advantage of these methods is their ability to be applied in non-linear systems, a drawback is the large calculation power and the long time required for calculations.

\subsection{The sum of weighted accelerations method}

The sum of weighted accelerations technique (SWAT) helps in force identification on the basis of vibration acceleration signal responses summed with suitable weighting [32]. Summing signals in the time domain has low sensitivity to numerical errors. The only obstacle which can be encountered when applying these methods is the definition of weight values for scaling time histories. There are two ways to designate weight. The first requires knowledge of the mode shapes of the system in a free state, the second requires that the history of vibration decay is possessed.

The limitation of the method is the lack of possibilities for calculating the spatial distribution of forces, it only allows the calculation of the sum of all external forces and moments regarding the center of mass. However, for many applications such knowledge is sufficient, and simplified calculations increase its robustness to measurement noise.

The way this method is realized can be described in two stages. Firstly, the dependency between internal forces should be introduced, and as a result of these displacements, modal coordinates. In the second step, it is necessary to weight and calculate the force present on the basis of the sum of weighted accelerations. The mathematical apparatus of the method is based on modal transformation.

Due to some numerical issues the number of measured accelerations must be equal to the number of modes used for calculations.

\subsection{Method based on state estimation}

The next method of force identification, which was imported from automatics, uses the concept of state estimation and prediction of inputs. It can be based on various principles, two most commonly used are based on Kalman filter [33-36] or state observer [37, 38] with unknown input signals. This type of observer, on the basis of the system responses signals, identifies its states as well as input signals. The method of force identification using such an observer is resistant to measurement noise and may operate in real time. Details of the design procedure for this type of observer can be found in [39].

\subsection{Parametric transfer function method}

The use of regressive parametric models for the identification of input signals can be seen in automatics. Adaptation of this method for mechanical systems and force identification can be found in multiple works [40, 41]. Its basic stages are: selection of the structure and identification of 
the regressive parametric model, then inversion of the model and input to the inverse model of the response signal, most often in vibration acceleration form, with the aim of calculating the forces causing the response. The basic problem for solutions is therefore inverting regressive models. In order to generate responses for an inverse linear dynamic model, it is necessary for it to be proper or strictly proper [42], linear, stationary and minimum-phase.

\subsection{Sample Force Dictionary Method}

An interesting method of impulse load reconstruction was presented in [43]. Authors aim to reconstruct not only time history of acting force but also place of an impact. They claim that in most practical cases the external loads are not arbitrary distributed in time and space and these a priori information should be taken into account in the estimation process. In case of an impact acting on a structure, the force history is mainly defined by the magnitude and the contact duration of the colliding bodies. The profile of the force history looks approximately like the pulse function shown. Now if one determines this shape function, then the force history of an impact depends only on the pulse width $t_{w}$, the magnitude value of this pulse $a_{t w} ; \mathrm{tm}$ and time at which the magnitude is reached $t m$. Thus, the external force history can by described as function of these parameters. The shape function can be normalized so that the magnitude becomes a scaling factor of the shape function. Shape functions may be known from experimental investigations or approximated by appropriate impact models. However, if the impact is intended to be reconstructed using measured structural responses the relation between response magnitude of and force magnitude needs to be identified in form of impulse responses or Markov parameters.

A similar solution for frequency domain was proposed by [44].

\section{STATISTICAL APPROACH TO FORCE IDENTIFICATION}

Methods presented in this section, along with soft computing approaches presented in sec. 6 can be applied when there is insufficient knowledge on the subject of the object dynamics to formulate deterministic dependencies, which allow the calculation of forces, when the dynamics are so complicated that their calculation would be impossible to perform with the help of deterministic dependencies or when input information is uncertain. Section is devoted to methods based on multiple regression and inverse structural filter.

\subsection{Force identification using multiple regression}

Identification of operational forces using the method of multiple regression allows the estimation of forces acting on a structure during its operation in real time. It is effective at various states of loading and working conditions. In order to utilize this method, firstly the connection between the identified force $f$ and the measured responses $y_{r}$ should be formulated as a function of $y_{r}$ and regression coefficients. These coefficients are then found using e.g. an optimization approach [45, 46].

In order to identify forces with the help of regression methods, data is necessary for estimation of the regressive model. It should be divided into two parts: the first for model estimation, the second for its verification. More on the subject of regression analysis can be found in the specialist literature concerning this type of problem [47]. The great advantage of methods based on regression analysis is the fact that force may be estimated on the basis of knowledge of process variables. In such cases, it is not necessary to perform additional measurements of structure response, which are often very difficult or almost impossible to perform.

\subsection{Inverse structural filter}

The method of the inverse structural filter is used for force identification in non-minimum-phase and non-collocated systems [48]. An example of such cases is the problem of forces developing in wheel-rail systems. Calculating forces with the help of an inverse structural filter is performed using the formula:

$$
f_{k}=\sum_{i=0}^{N_{r}-1} r_{i} \cdot y_{k-1+l}
$$

where $f_{k}$ is the $k$-th sample of the identified force vector, $y$ is the response vector, while $r i$ is the $i$-th filter coefficient. Filter order is defined by $N r$, while $l$ represents the non-casual lead of the filter. For systems with multiple inputs and outputs (MIMO), the filter coefficients $r$ are matrices of the size $n_{a} \times n_{s} \quad$ (number of inputs $\times$ number of outputs). These coefficients are the pseudoinverse Markov parameters of the system. Designating their values is connected with the necessity to solve the deconvolution problem.

\section{SOFT COMPUTING FOR FORCE IDENTIFICATION}

Similarly to methods described in the previous section, soft computing (SC) approaches are used in cases when there is not enough information for calculation of a deterministic model. There are three categories of SC methods, which are arguably the most common and are broadly employed in different tasks related to mechanical engineering: artificial neural networks (ANNs), evolutionary and other natural optimization algorithms and fuzzy approaches. Although they are often used in task of force identification, particularly for impact force reconstruction [49, 50], compilation of theory related to their usage would significantly exceed the scope of the paper. For that reason authors focus only on brief explanation of their principles of operation and scope of operational perspectives, 
without recall of particular equations and algorithms. A good introduction to SC methods from mechanical engineering point of view can be found in tutorial by Worden et al. [51]. Brief summary of their usage in various fields of mechanical engineering is included e.g. in $[52,53]$.

\subsection{Force identification with use of Artificial Neural Networks}

Artificial neural networks are constructed from a definite number of basic calculation units known as neurons. Particular types of neural networks differ in the architecture of neurons placement, flow of information between them, activation functions, methods of learning, etc. and are widely discussed in the literature $[51,54,55]$. The application of artificial neural networks for force identification is described in multiple papers [49, 50, 56-60]. Because a machine as a dynamic system may find itself in various phases of loading (run-up, work with full load, without load, run-down etc.), in order to accurately identify the operational forces large amount of training data is usually required. Cooperation of several networks was reported to render better results in such cases: The problem can be assigned to one of the categories by one network and then passed to a "specialist" - that is: a network trained on similar type of data [62].

\subsection{Force identification with use of Fuzzy Logic}

Similarly to artificial neural networks, fuzzy logic can be used for force identification [63]. With its help, it is possible to formally define imprecise and multi-meaning terms such as large force or small force which allows for easy generalization and incorporation of expert knowledge into the system . In the design of fuzzy sets, the most important aspect is the definition of the so-called consideration set. In the case of the multi-meaning term of "large force", other values will be considered as too large if the consideration set is limited to the interval $[0,2 \mathrm{~N}]$, and others if the range of change is $[0,10000 \mathrm{~N}]$.

The identification of forces with this method takes place according to similar algorithms to those in the method using artificial neural networks, presented in the previous sub-section. Practical application of fuzzy logic used for force identification revealed that fuzzy reasoning more effectively classifies the work state of the machine, but is worse at identifying force in relation to neural networks [58].

A common approach rely on combination of ANN-based architecture with fuzzy reasoning to build neuro-fuzzy systems. Such systems are recently more and more popular in tasks of dynamic system identification and force identification [6466].

\subsection{Force identification with natural optimization algorithms}

The concept of using natural optimization algorithms for force identification in mechanical structures is based on the objective function minimization defined on the difference between measured system responses and responses obtained from the model simulation [24]. This is the objective function minimization method described in Sub-section 4.1. For minimization of the objective function purposes many different natural optimization methods can be used, including evolutionary and genetic algorithms [59, 61, 67, 68], swarm-intelligence algorithms [29, 60] and others. They are used due to the large scale of the problem, the multi-modality of the optimization problem, as well as the existence of many local minima, which in practice hinder the process of force identification (solutions uniqueness).

In the task of force identification such solutions are often used as a primary step which is later followed by local optimization algorithms [69] or as a model-identification step [70].

\section{SUMMARY}

The authors presented a detailed review of methods for identification of excitation forces, divided into frequency-domain-based, timedomain-based, employing statistical dependencies and soft computing approach. The idea of this review was to enable the reader to make a preliminary assessment of the suitability of the methods without further literature studies. Works that extend the scope of presented methods are, however, pointed out and briefly described.

\section{SOURCE OF FUNDING}

The work presented in this paper was supported by the National Science Centre in Poland under the research project no. 2016/21/D/ST8/01678.

\section{REFERENCES}

1. Balageas D, Fritzen CP, Guemes A. Structural Health Monitoring. ISTE Ltd, London, UK, 2006.

2. Sanchez J, Benaroya H. Review of force reconstruction techniques. Journal of Sound and Vibration. 2014; 333(14):2999-3018. https://doi.org/10.1016/j.jsv.2014.02.025.

3. Radkowski S, Zawisza M. Failure oriented diagnostic models in condition monitoring. Diagnostyka. 2009; 4(52):93-97.

4. Uhl T. The inverse identification problem and its technical application. Archive of Applied Mechanics. 2007; 77(5):325-337.

5. Omidi E, Mahmoodi NS, Shepard SW. Multi positive feedback control method for active vibration suppression in exible structures. Mechatronics. 2019; 33:23-33. https://doi.org/10.1111/str.12258

6. Donoughue PO, Robin O, Berry A. Time-resolved identification of mechanical loadings on plates using 
the virtual fields method and defectometry measurements. Strain. 2018; 1-14, 2018. https://doi.org/10.1111/str.12258

7. Mostafavi M, Collins DM, Peel MJ, Reinhard C, Barhli SM, Mills R, Marshall MB, Dwyer-Joyce RS, Connolley T. Dynamic contact strain measurement by time resolved stroboscopic energy dispersive synchrotron X ray diffraction. Strain. 2017; 53:1-13, 2017. https://doi.org/10.1111/str.12221.

8. Grediac M, Sur F, Blaysat B. The Grid Method for In-plane Displacement and Strain Measurement: A Review and Analysis. Strain. 2016; 52:205-243. https://doi.org/10.1111/str.12182.

9. Otsuka T, Okada T, Ikeno T, Shiomi K, Okuma M. Force identification of an outboard engine by experimental means of linear structural modeling and equivalent force transformation. Journal of Sound and Vibration. 2017; 308:541-547.

https://doi.org/10.1016/j.jsv.2007.04.004.

10. Parloo E, Verboven P, Guillaume P, Van Overmeire $M$. Force identification by means of in-operation modal models. Journal of Sound and Vibration. 2003; 262:161-173.

11. Cardi AA, Adams DE, Walsh S. Ceramic Body Armor Single Impact Force Identification on a Compliant Torso Using Acceleration Response Mapping. Structural Health Monitoring/ 2016; 5(4). https://doi.org/10.1177/1475921706067763

12. Pons J, Jezequel L, Laborde J. Coherence analysis of transfer function and polynomial chaos for the measurement of vibratory forces by inverse method. In Proceeding of ISMA2016 including USD2016, 2016.

13. Dobson B, Rider E. A review of the indirect calculation of excitation forces from measured structural response data. Proceedings of the Institution of Mechanical Engineering Part C Journal of Mechanical Engineering Science. 1990; 204:69-75.

14. Rust A, Edlinger I. Active path tracking for vehicle noise source identification. Sound And Vibration. 2002; 36:14.

15. Wyckaert K, Van der Auweraer H. Operational Analysis, Transfer Paths Analysis, Modal Analysis, Tools to Understand Road Noise Problems in Cars. In Proceedings of SAE Noise and Vibration Conference. 1995; 139-143.

16. Zhang Q, Allemang RJ, Brown DL. Modal filter: Concept and applications. In Proceedings of 8th IMAC, 1990; 487-496.

17. Mendrok K. Force identification with use of spatial filter based on ODS. Diagnostyka. 2015; 16(1):23-28.

18. Mendrok K, Bochenska M, Dworakowski Z. Effectiveness evaluation of the damage localization with a local spatial filtration under variable external conditions. Diagnostyka. 2019; 20(1):55-61. https://doi.org/10.29354/diag/100406.

19. Shih CY, Zhang Q, Allemang RJ. Force identification by using principle and modal coordinate transformation method. Vibration Analysis Techniques and Applications, ASME publication DE. 1989; 18(4):303-309.

20. Li J. Application of mutual energy theorem for determining unknown force sources. In Proceedings of Internoise 88, Avignon, France. 1988.

21. Nelson PA, Curtis ARD, Elliott SJ, Bullmore AJ. The minimum power output of free field point sources and the active control of sound. Journal of Sound and Vibration. 1987; 116(3):397-414.
22. Giergiel J, Uhl T. Identification of the input impact type forces in mechanical systems. The Archives of Transport. 1989; 1(1):29-52.

23. Giergiel J, Uhl T. Identification of the impact force in mechanical system. Archives of Machine Design. 1989; XXXVI(2-3).

24. Pieczara J. Application of genetic algorithms for identification of load vector. Machine Dynamics Problems. 2005; 29(2):115-128.

25. Busby HR, Trujillo DM. Optimal Regularization of an inverse dynamic problem. Computers and Structures. 1997; 63(2):243-248.

26. Jankowski L. On-line identification of dynamic loads. Structural and Multidisciplinary Optimization. 2009; 37(6):609-623.

27. Holnicki-Szulc J, Gierliski J. Structural Analysis, Design and Control by the Virtual Distortion Method. Wiley, Chichester. 1995.

28. Zhu T, Xiao S, Yang G. Force identification in time domain based on dynamic programming. Applied Mathematics and Computation. 2014; 235:226-234. https://doi.org/10.1016/j.amc.2014.03.008.

29. El-Bakari A, Teidj S, Khamlichi A, Jacquelin E. Predictability of Impact Force Localization by Using the Optimization Technique. Procedia Technology. 2016; 22:94-100. https://doi.org/10.1016/j.protcy.2016.01.015.

30. Qiao B, Zhang X, Gao J, Liu R, Chen X. Sparse deconvolution for the large-scale ill-posed inverse problem of impact force reconstruction. Mechanical Systems and Signal Processing. 2016; 85:93-115. https://doi.org/10.1016/j.ymssp.2016.05.046

31. Qiao B, Zhang X, Gao J, Chen X. Impact-force sparse reconstruction from highly incomplete and inaccurate measurements. Journal of Sound and Vibration. 2016; 376:72-94.

https://doi.org/10.1016/j.jsv.2016.04.040.

32. Carne TG, Randy ML, Bateman VI. Force reconstruction using the sum of weighted accelerations technique - max-at procedure. In Proceedings of the 12th International Modal Analysis Conference, 1994; 2251:1054 - 1062.

33. Maes K, De Roeck G, Iliopoulos A, Weijtjens W, Devriendt C, Lombaert G. Kalman filter based strain estimation for fatigue assessment of an offshore monopile wind turbine. In Proceeding of ISMA2016 including USD2016. 2016.

34. Tamarozzi T, Risaliti E, Rottiers W, Janssens K, Desmet W. Noise, ill-conditioning and sensor placement analysis for force estimation through virtual sensing. In Proceeding of ISMA2016 including USD2016. 2016.

35. Yan G, Sun H, Buyukozturk O. Impact load identification for composite structures using Bayesian regularization and unscented Kalman filter. 2016. https://doi.org/10.1016/j.jsv.2008.06.051

36. Zhang CD, Xu YL. Structural damage identification via response reconstruction under unknown excitation. Structural Health Monitoring. 2016; 24(8):1-11. https://doi.org/10.1002/stc.1953.

37. Klinkov M, Fritzen CP. Online estimation of external loads from dynamic measurements. In Proceedings of ISMA. 2006; 3957-3968.

38. Rubio-Hervas J, Reyhanoglu M, MacKunis W. Observer-based Sliding Mode Control of Rijketype Combustion Instability. Low Frequency Noise, Vibration and Active Control. 2015; 34(2):201-218. https://doi.org/10.1260/0263-0923.34.2.201. 
39. Ha QP, Trinh H. State and input simultaneous estimation for a class of nonlinear systems. Automatica. 2004; 40:1779-1785.

40. Czop P, Uhl T. Load identification methods based on parametric models for mechanical structures. In Proceedings of the 8th IEEE International Conference on Methods and Models in Automation and Robotics MMAR. 2002; 1015-1020.

41. Mendrok K, Kurowski P, Uhl T. Operational forces identification from helicopter model in-flight data with the use of inverted regressive parametric models. In Proceedings of the ASME 2008 International Design Engineering Technical Conferences \& Computers and Information in Engineering Conference, New York, USA. 2008.

42. Larminat P, Thomas Y. Automatics of Linear Systems, vol 2 (in French). Flammarion Sciences, Paris, 1977.

43. Ginsberg D, Fritzen CP. Impact identification and localization using a sample-force-dictionary General Theory and its applications to beam structures. Structural Monitoring and Maintenance. 2016; 3(3):195-214.

https://doi.org/10.12989/smm.2016.3.3.195

44. Rezayat A, Nassiri V, De Pauw B, Ertveldt J, Vanlanduit S, Guillaume P. Identification of dynamic forces using group-sparsity in frequency domain. Mechanical Systems and Signal Processing. 2016; 70-71:756-768.

https://doi.org/10.1016/j.ymssp.2015.09.015

45. Haas DJ, Imber R. Identification of helicopter component loads using multiple regression. Journal of Aircraft. 1994; 31(4):929-935.

46. Zion L. Predicting fatigue loads using regression diagnostics. In Proceedings of The American Helicopter Society Annual Forum. 1994; 1337-1358.

47. Draper NR, Smith H. Applied Regression Analysis. Wiley-Interscience, Warsaw, Poland, 3rd edition. 1998.

48. Stelzner DA, Kammer DC. Input force estimation using an inverse structural filter. In Proceedings of 17th IMAC, Orlando, Florida, USA. 1999; 954-960

49. Staszewski WJ, Worden K, Wardle R, Tomlinson GR. Fail-safe sensor distributions for impact detection in composite. Smart Materials and Structures. 2000; 9:298-303.

50. Ghajari M, Sharif-Khodaei Z, Aliabadi MH, Apicella A. Identification of impact force for smart composite stiffened panels. Smart Materials and Structures. 2013; 22:13. https://doi.org/10.1088/0964$1726 / 22 / 8 / 085014$.

51. Worden K, Staszewski WJ, Hensman JJ. Natural computing for mechanical systems research: A tutorial overview. Mechanical Systems and Signal Processing. 2011; 25(1):4-111.

https://doi.org/10.1016/i.ymssp.2010.07.013.

52. Skliros C, Miguez ME, Fakhre A, Jennions J. A review of model based and data driven methods targeting hardware systems diagnostics. Diagnostyka. 2018; 20(1):3-21.

https://doi.org/10.29354/diag/99603

53. Hossain MS, Chao OZ, Ismail Z, Noroozi S, Yee KS, Artificial Neural Networks for Vibration Based Inverse Parametric Identifications: A Review. Applied Soft Computing Journal. 2016; 52:203-219. https://doi.org/10.1016/j.asoc.2016.12.014.
54. Norgaard M, Ravn O, Poulsen NK, Hansen LK. Neural network for modeling and control of dynamic systems. Springer- Verlag, London, UK, 2000.

55. Haykin S. Neural Networks A Comprehensive Foundation. Pearson Prentice Hall, 2001.

56. McCool KM, Flitter LA, Haas DJ. Development and flight test evaluation of a rotor system load monitoring technology. Journal of American Helicopter Society. 2000; 45:19-27.

57. Haas DJ, Milano J, Flitter L. Prediction of Helicopter Component Loads Using Neural Networks. Journal of American Helicopter Society. 1995; 40:72-82.

58. Goral G, Bydon S, Uhl T. Intelligent transducers of in-operational loads in construction fatigue monitoring. Machine Dynamics Problems. 2002; 26(2/3):73-88.

59. $\mathrm{Fu} \mathrm{Z}$, Cheng W. Force Identification by Using Support Vector Machine and Differential Evolution Optimization. Adv. in Neural Network Research \& Appli, LNEE 67. 2010; 793-801.

60. Fu Z, Cheng W, Yang Y. Force Identification by Using SVM and CPSO Technique. In ICSI 2010, Part II, LNCS 6146. 2010; 140-148.

61. Worden K, Staszewski WJ. Impact Location and Quantification on a Composite Panel using Neural Networks and a Genetic Algorithm. Strain. 2000; 36(2):61-68.

62. LeClerc JR, Worden K, Staszewski WJ, Haywood J. Impact detection in an aircraft composite panel - A neural-network approach. Journal of Sound and Vibration. 2007; 299(3):672-682.

63. Lee MH, Chen TC. Intelligent fuzzy weighted input estimation method for the forces generated by an operating rotating machine. Measurement: Journal of the International Measurement Confederation. 2011; 44(5):917- 926. https://doi.org/10.1016/j.measurement.2011.02.013

64. Jiang X, Mahadevan S, Yuan Y. Fuzzy stochastic neural network model for structural system identification. Mechanical Systems and Signal Processing. 2016; 82:1-18. https://doi.org/10.1016/j.ymssp.2016.05.030.

65. Mozaffari A, Behzadipour S, Kohani M. Identifying the tool-tissue force in robotic laparoscopic surgery using neuro-evolutionary fuzzy systems and a synchronous self-learning hyper level supervisor. Applied Soft Computing Journal. 2014; 14(PART A):12-30. https://doi.org/10.1016/j.asoc.2013.09.023.

66. Golob M, Tovornik B. Input-output modelling with decomposed neuro-fuzzy ARX model. Neurocomputing. 2008;71(4-6):875-884.

67. Li S, Liu Y. Identification of vibration loads on hydro generator by using hybrid genetic algorithm. Acta Mechanica Sinica. 2006;22(6):603-610.

68. Xia Z, Mao K, Wei S, Wang X, Fang Y, Yang S. Application of genetic algorithm support vector regression model to predict damping of cantilever beam with particle damper. Journal of Low Frequency Noise Vibration and Active Control. 2017;36(2):138-147.

https://doi.org/10.1177/0263092317711987

69. Talebitooti R, Torabi M. Identification of tire force characteristics using a Hybrid method. Applied Soft Computing Journal 2016;40:70-85. https://doi.org/10.1016/j.asoc.2015.09.053.

70. Si L, Baier H. An in situ ensemble impact monitoring and identification technique for fiber composite structures under multiple disturbances. 
Structural Health Monitoring. 2016; 15(3):247-265. https://doi.org/10.1177/1475921716636334.

Received 2019-03-15

Accepted 2019-06-25

Available online 2019-07-01

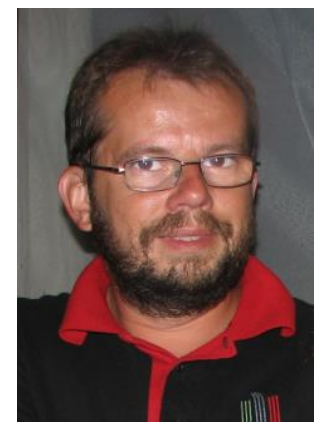

\section{DSc. PhD. Krzysztof} MENDROK

is an Associate Professor in the Department of Robotics and Mechatronics of the AGH University of Science and Technology. $\mathrm{He}$ is interested in development and application of various SHM algorithms. He mainly deals with low frequency vibration based methods for damage detection and inverse dynamic problem for excitation identification.

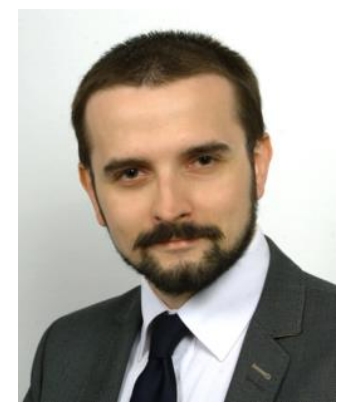

\section{$\mathrm{PhD}$. Ziemowit}

\section{DWORAKOWSKI}

is a researcher in the Department of Robotics and Mechatronics of the AGH University of Science and Technology in Krakow. His research interests include soft computing applied in mechanical engineering. Especially, he is interested in pattern recognition and novelty detection techniques for structural health monitoring data and design of adaptive identification and control systems. 